\title{
Development of a Method for a Sensitive Simultaneous Determination of Dopamine and Paracetamol in Biological Samples and Pharmaceutical Preparations
}

\author{
Ali Babaei, ${ }^{1,2}$ Aliyeh Dehdashti, ${ }^{1}$ and Mohammad Afrasiabi ${ }^{3}$ \\ ${ }^{1}$ Department of Chemistry, Arak University, Arak, P.O. Box 38156-879, Iran \\ ${ }^{2}$ Research Center for Nanotechnology, Arak University, P.O. Box 38156-879, Iran \\ ${ }^{3}$ Department of Chemistry, Islamic Azad University, Shoushtar Branch, Shoushtar, Iran
}

Correspondence should be addressed to Ali Babaei, a_babaei07@yahoo.com

Received 14 March 2011; Accepted 3 May 2011

Academic Editor: Shane Peper

Copyright ( $\odot 2011$ Ali Babaei et al. This is an open access article distributed under the Creative Commons Attribution License, which permits unrestricted use, distribution, and reproduction in any medium, provided the original work is properly cited.

\begin{abstract}
A chemically modified electrode is constructed based on multiwalled carbon nanotube-modified glassy carbon electrode (MWCNTs/GCE). The measurements were carried out by application of differential pulse voltammetry (DPV), cyclic voltammetry $(\mathrm{CV})$, and chronoamperometry (CA) methods. Application of DPV method showed wide linear range of DA from $1 \mu \mathrm{M}$ to $540 \mu \mathrm{M}$ and a detection limit of $0.098 \mu \mathrm{M}(\mathrm{S} / \mathrm{N}=3)$. The linear range of PAR of $3 \mu \mathrm{M}$ to $300 \mu \mathrm{M}$ and a detection limit of $0.15 \mu \mathrm{M}$, were obtained. The modified electrode showed electrochemical responses with high sensitivity, high selectivity, and excellent stability for DA and PAR determination at optimal conditions, which makes it a suitable sensor for simultaneous submicromolar detection of DA and PAR in solutions. The analytical performance of this sensor has been evaluated for detection of DA and PAR in human serum, human urine, and pharmaceutical preparation with satisfactory results.
\end{abstract}

\section{Introduction}

In the last years, carbon nanotubes (CNTs) have been used as a very attractive material for a wide range of applications due to their unique structural, electronic, mechanical, geometric, and chemical properties [1]. The subtle electronic behavior of CNTs reveals that they have a high electrocatalytic effect when used as an electrode [2]. Recently, a carbon nanotube-modified solid electrode has attracted much attention because of its excellent electrochemical properties. Among them, glassy carbons (GCEs) have been widely used compared to metal electrodes due to thier biocompatibility with tissue, having low residual current over a wide potential range and having minimal propensity to show a deteriorated response as a result of electrode fouling [3].

Dopamine (3,4-dihydroxyphenylethylaine) is an important neurotransmitter of the catecholamine group that exists in the mammalian central nervous system and is well characterized by its electrochemical activity [4], and it plays an important role in various biological, pharmacological processes [5]. Some diseases are related to the change of dopamine levels. Parkinson's disease is one of them.

Paracetamol ( $N$-acetyl- $p$-aminophenol) (PAR), also known as acetaminophen, is a widely used analgesic antipyretic drug. Its action is similar to aspirin and is a suitable alternative for the patients who are sensitive to aspirin. It is also found that overdoses of PAR will damage liver and kidney. Unfortunately, its ready access has resulted in its increased use in effort suicide $[6,7]$. The major catecholamine is dopamine. This substance breaks down into other compounds, which leave our body through our urine. A urine test can be done to measure the level of catecholamine in our body. The important drug such as paracetamol will interfere with the catecholamine measurement in biological samples [8]. Animal model studies have shown that PAR might protect neurons from degeneration. For example, PAR can protect primary rat embryonic DA neurons from glutamate toxicity. Also, PAR administration 
at antinociceptive doses affects serotonin (5-HT) and dopamine levels in various brain areas and the spinal cord in rate [9].

Various methods have been studied for the single determination of DA or PAR, for example, in detecting DA, HPLC [10], as fluorometry [11], UV-vis [12], and, in detecting PAR, spectrophotometry [13-17], near infrared transmittance spectroscopy [18], Fourier transform infrared spectrophotometry [19], spectrofluorometry [20, 21], and chromatography $[22,23]$. However, the majority of these methods suffer from some disadvantages such as high costs, long analysis times, and requirement for sample pretreatment, and in some cases low sensitivity and selectivity that makes them unsuitable for routine analysis. Consequently the development of inexpensive, simple, sensitive, and reliable analytical methods for simultaneous determination of DA and PAR is of considerable importance.

\section{Experimental}

2.1. Reagents and Solutions. All chemicals were of analytical grade and used without further purification. DA and PAR were obtained from Acros and Merck chemical companies, respectively. Multiwalled carbon nanotubes (MWCNTs) (>95 wt\%, 5-20 nm) were purchased from PlasmaChem $\mathrm{GmbH}$ company. Stock standard solutions of $10 \mathrm{mM}$ DA and $10 \mathrm{mM}$ PAR were freshly prepared in $0.1 \mathrm{M}$ phosphate buffers of $\mathrm{pH}$ 7. All subsequent DA and PAR solutions used were prepared by diluting these standard solutions with $0.1 \mathrm{M}$ phosphate buffer ( $\mathrm{pH} 7)$. The $0.1 \mathrm{M}$ phosphate buffer solutions (PBSs) used were prepared by dissolving appropriate amounts of sodium hydrogen phosphate and sodium dihydrogen phosphate in triply distilled water. Electrochemical experiments on the DA and PAR were carried out in $0.1 \mathrm{M} \mathrm{PBS}$ at $\mathrm{pH}$ 7. Fresh human serum samples were prepared from Razi Institute of Vaccine and Serum Company (Tehran, Iran). The serum and urine sample were filtered and diluted 50 times using a $0.1 \mathrm{M}$ PBS of pH 7 and applied for the determination of the recovery in spiking of DA and PAR. A DA injection solution was from Caspian Tamin Pharmaceutical Company (Rasht, Iran), and PAR tablets were from Pharma Chemi Darou Company (Tehran, Iran). Ten tablets of PAR were accurately weighed and powdered in a mortar. An amount equivalent to one in tablet content was dissolved in $70 \mathrm{~mL}$ of $0.1 \mathrm{M}$ PBS ( $\mathrm{pH} 7$ ). After 10-minute sonication, the solutions were filtered and the residue was washed three times with $10 \mathrm{~mL}$ of the buffer solvent, then the volume was adjusted to $100 \mathrm{~mL}$ with the same solvent. This solution was diluted 1000 times for PAR determination using a $0.1 \mathrm{MPBS}$ of $\mathrm{pH}$ 7. Also, the injection solution of DA was diluted 5000 times. These solutions were applied for the determination of the recovery in spiking of PAR and DA compounds.

2.2. Instrumentation. All the voltammetric measurements were carried out using carbon nanotube-modified glassy carbon electrode (MWCNTs/GCE) as a working electrode, $\mathrm{Ag} / \mathrm{AgCl} / 3 \mathrm{M} \mathrm{KCl}$ as a reference electrode, and platinum wire as an auxiliary electrode. DPV, CV, and CA experiments were carried out using an Autolab PGSTAT 30 Potentiostat Galvanostat (Eco Chemie, The Netherlands) coupled with a 663 VA stand (Metrohm Switzerland). All potentials given are with respect to the potential of the reference electrode. $\mathrm{pH}$ measurements were performed with a Metrohm $744 \mathrm{pH}$ meter using a combination glass electrode.

2.3. Modification of the Electrodes. A glassy carbon electrode (GCE, 3-mm diameter, Metrohm) was polished with 0.3 and $0.05 \mu \mathrm{m}$ aluminum slurry and rinsed thoroughly with triply distilled water. The GC electrode was cleaned by ultrasonic agitation for $5 \mathrm{~min}$ in ethanol and then distilled water, individually. The electrode was dried under nitrogen gas flow.

A stock solution of $1 \mathrm{mg} \cdot \mathrm{mL}^{-1}$ MWCNTs-DMF was prepared by dispersing $1 \mathrm{mg}$ of MWCNTs in $1 \mathrm{~mL}$ DMF. $30 \mu \mathrm{L}$ of MWCNTs-DMF solution was coated on GC electrode surface. The electrode was dried in room temperature to obtain MWCNTs/GCE. The fabricated MWCNTs/GCE was placed in the electrochemical cell containing 0.1 M PBS, and several cycles in the potential windows of -0.2 to $0.7 \mathrm{~V}$ were applied using CV method to obtain stable responses.

2.4. General Procedure. $10 \mathrm{~mL}$ solutions containing appropriate amounts of DA and PAR in $0.1 \mathrm{M}$ PBS at $\mathrm{pH} 7$ were transferred into the voltammetric cell. The voltammograms were recorded by applying positive-going potential from -0.1 to $0.6 \mathrm{~V}$. The voltammograms showed anodic peaks around 0.14 and $0.33 \mathrm{~V}$ corresponding to DA and PAR compounds whose heights are proportional to their concentrations in solutions. The calibration curves were obtained by plotting anodic peak currents of DA and PAR versus the corresponding concentrations. All experiments were carried out under open-circuit condition.

After each measurement, the MWCNTs/GCE was regenerated by thoroughly washing the electrode with triply distilled water and then 5\% sodium hydroxide solution consecutively. Finally, the electrode was rinsed carefully with distilled water to remove all adsorbate from electrode surface and provide fresh surface for the next experiments.

\section{Results and Discussion}

3.1. Scanning Electron Microscopy (SEM) Analysis of MWCNTs/GCE. SEM was used to observe directly the morphology of MWCNTs/GCE. The SEM images of the MWCNTs/GCE (Figure 1) showed that the GCE surface was mostly covered with homogenous MWCNTs, which were in the form of small bundles or single tubes.

3.2. Electrochemical Behavior of DA and PAR on MWC$N T s / G C E$. The cyclic voltammograms were recorded for $70 \mu \mathrm{M}$ DA and $50 \mu \mathrm{M}$ PAR at MWCNTs/GCE as shown in Figure 2. Figure 2 (a) shows the voltammograms of $70 \mu \mathrm{M}$ of DA and $50 \mu \mathrm{M}$ of PAR in PBS ( $\mathrm{pH}$ of 7) at GC. Figure 2(b) displays the voltammograms of DA and PAR at the same conditions as Figure 2(a) at MWCNTs/GCE. As can be 


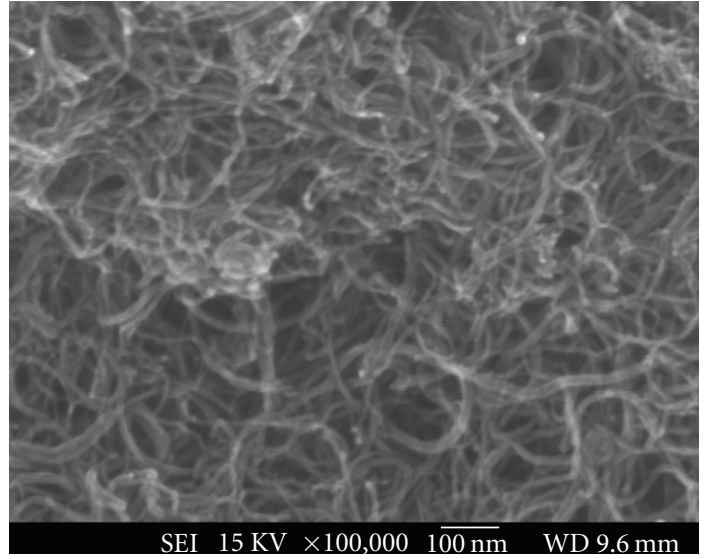

FIgure 1: SEM image of MWCNTs film on a GCE.

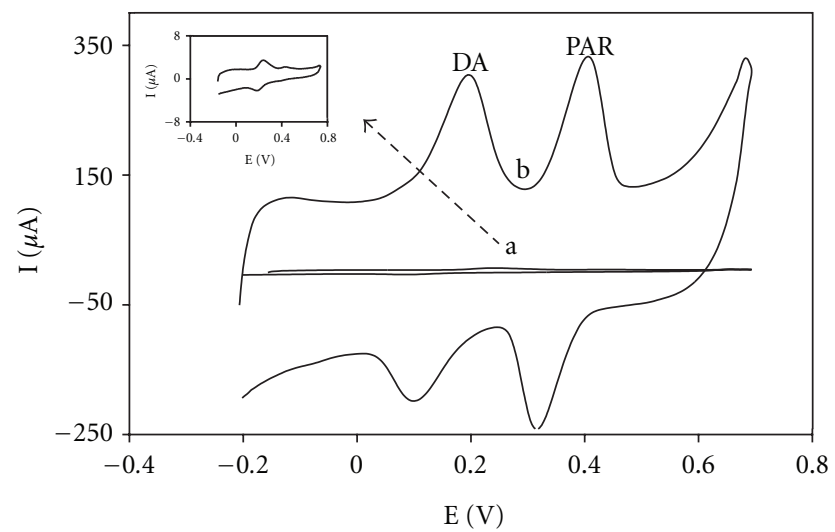

FIgURE 2: Cyclic voltammograms of $70 \mu \mathrm{M}$ DA and $50 \mu \mathrm{M}$ PAR at MWCNTs/GCE in $0.1 \mathrm{M}$ phosphate buffer solution ( $\mathrm{pH} 7$ ) at scan rate of $100 \mathrm{mVs}^{-1}$.

seen from the GC a very small oxidation peak is observed for DA and PAR oxidations. The CVs of DA and PAR at MWCNTs/GCE showed excellent improvement in oxidation peak currents for DA and PAR oxidations (Figure 2(b)).

The effect of potential scan rate on the oxidation responses of DA and PAR was investigated in the 10$400 \mathrm{mVs}^{-1}$ range of scan rate (not shown). A linear relationship between the anodic peak currents and scan rate was found for DA and PAR as follows:

$$
\operatorname{Ipa}(\mu \mathrm{A})=0.715 \nu\left(\mathrm{mV} \mathrm{s}^{-1}\right)+10.36 \quad\left(\mathrm{R}^{2}=0.995\right) \quad \mathrm{DA},
$$

$\operatorname{Ipa}(\mu \mathrm{A})=0.882 \nu\left(\mathrm{mV} \mathrm{s}^{-1}\right)+6.157 \quad\left(\mathrm{R}^{2}=0.992\right) \quad$ PAR.

The linear relationship between peak currents and scan rates, suggesting the redox reactions of DA and PAR compounds at MWCNTs/GCE, are adsorption-controlled processes.

The differential pulse voltammograms recorded for DA and PAR at bare GCE and MWCNTs/GCE are shown in Figure 3. Figure 3(a) shows the voltammograms of $70 \mu \mathrm{M}$ of DA and $50 \mu \mathrm{M}$ of PAR in PBS (pH of 7) at GC. Figure 3 (b) displays the voltammograms of DA and PAR at the same conditions as Figure 3(a) at MWCNTs/GCE. As can be seen from the GC a very small oxidation peak is observed for DA and PAR oxidations. The DPVs of DA and PAR at

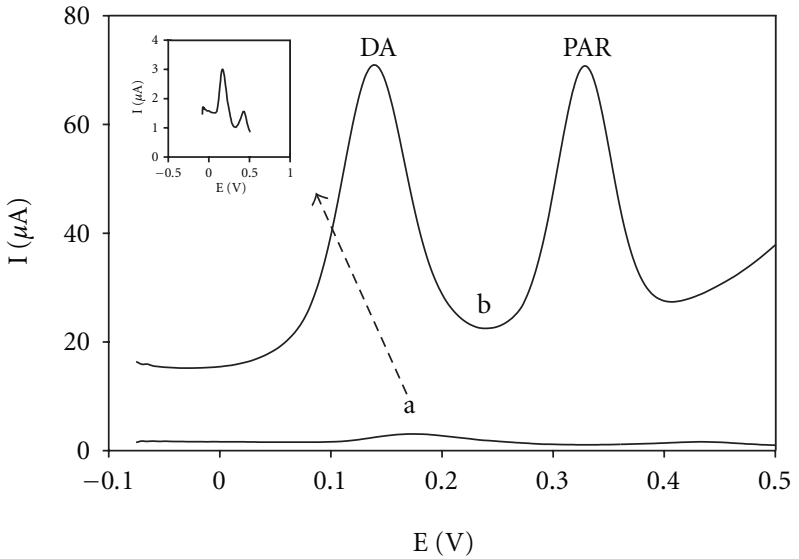

Figure 3: Differential pulse voltammograms of $70 \mu \mathrm{M}$ DA and $50 \mu \mathrm{M}$ PAR at (a) GC and (b) MWCNTs/GCE in $0.1 \mathrm{M}$ phosphate buffer solution ( $\mathrm{pH} 7$ ). Other conditions: open circuit, $t_{\mathrm{acc}}=60 \mathrm{~s}$, pulse amplitude $=50 \mathrm{mV}$, scan rate $=10 \mathrm{mV} \cdot \mathrm{s}^{-1}$, interval time $0.5 \mathrm{~s}$, modulation time $=0.2 \mathrm{~s}$, and step potential $=5 \mathrm{mV}$.

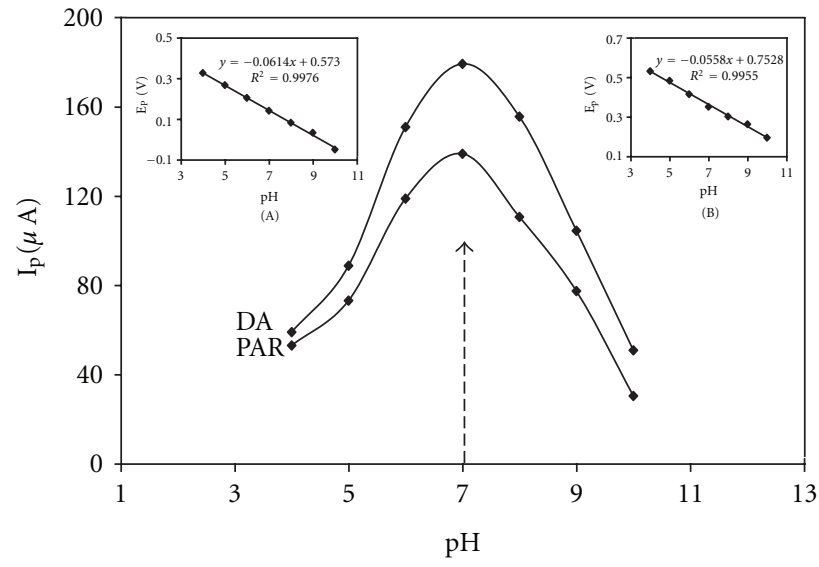

Figure 4: Effect of $\mathrm{pH}$ on the differential pulse voltammogram peak currents of oxidations of DA and PAR compounds at MWCNTs/GCE in phosphate buffer solutions. Concentrations: DA: $200 \mu \mathrm{M}$ and PAR: $200 \mu \mathrm{M}$. Insets: (A) plot of peak potential as a function of $\mathrm{pH}$ for DA. (B) Plot of peak potential as a function of $\mathrm{pH}$ for PAR.

MWCNTs/GCE showed excellent improvement in oxidation peak currents for DA and PAR oxidations (Figure 3(b)). The presence of MWCNTs could facilitate the electron transfer between electrode and the analytes; therefore the enhancements in the corresponding electrochemical oxidation peak currents were observed.

3.3. Effects of Solution $\mathrm{pH}$. The effect of $\mathrm{pH}$ of solutions on the electrochemical response of the MWCNTs/GCE toward the determination of $200 \mu \mathrm{M} \mathrm{DA}$ and 200 PAR was investigated using DPV method. Variations of peak current with respect to $\mathrm{pH}$ of the electrolyte in the $\mathrm{pH}$ range from 4 to 10 are shown in Figure 4. It can be seen that the anodic peak currents of DA and PAR increase with raising the solution $\mathrm{pH}$ until it reaches 7. However at higher $\mathrm{pH}$ the DA and PAR oxidation peak current starts to diminish. 


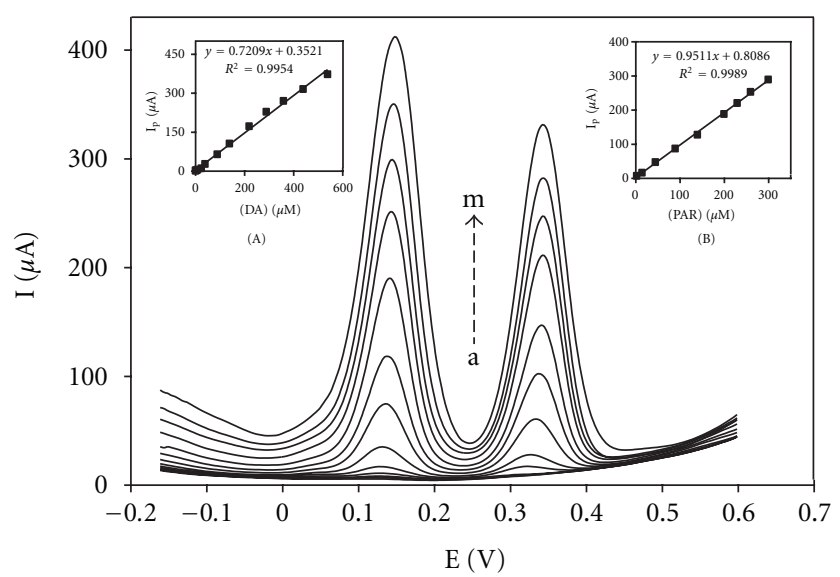

Figure 5: Differential pulse voltammograms for different concentrations of DA and PAR mixtures as (a) $1+0.5$, (b) $3+1$, (c) $5+$ 1.5 , (d) $10+2$, (e) $25+3$, (f) $40+15$, (g) $90+45$, (h) $140+90$, (i) $220+140$, (j) $290+200$, (k) $360+230$, (l) $440+260$, and (m) 540 +300 , respectively, in which the first value is the concentration of $\mathrm{DA}$ in $\mu \mathrm{M}$ and the second value is the concentration of PAR in $\mu \mathrm{M}$. Insets: (A) plot of peak currents as a function of DA concentration. (B) Plot of the peak currents as a function of PAR concentration.

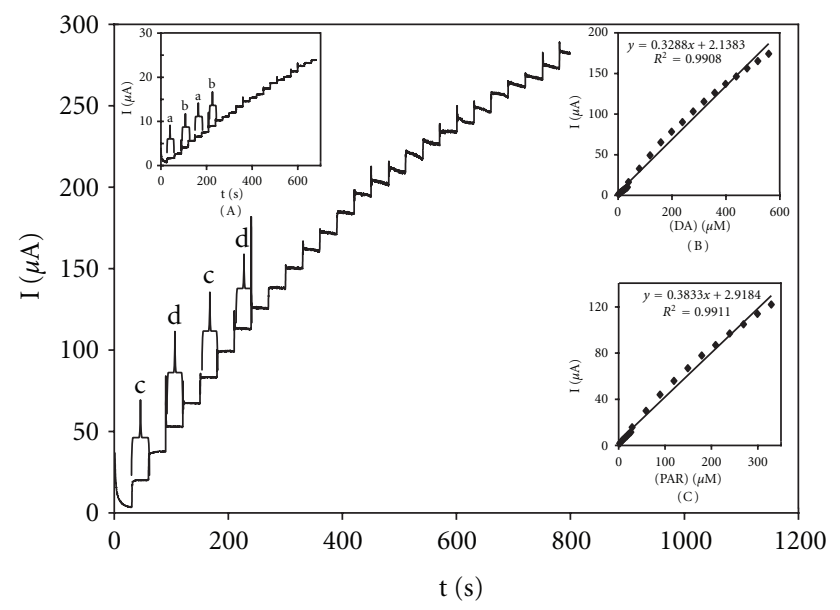

FIGURE 6: Hydrodynamic amperometric response at rotating MWCNTs / GCE (rotating speed $2500 \mathrm{rpm}$ ) held at $0.4 \mathrm{~V}$ in PBS (pH 7) for simultaneous determination of DA and PAR by successive additions of (a) $3 \mu \mathrm{M} \mathrm{DA}$, (b) $3 \mu \mathrm{M}$ PAR, (c) $40 \mu \mathrm{M} \mathrm{DA}$, and (d) $30 \mu \mathrm{M}$ PAR. Insets: (B) plot of peak currents as a function of DA concentration. (C) Plot of peak currents as a function of PAR concentration.

Therefore, the $\mathrm{pH}$ value of 7 , which is close to biological $\mathrm{pH}$ value, was chosen as an optimum solution $\mathrm{pH}$ for further experiments. Variation, of DA and PAR oxidation peak potential with $\mathrm{pH}$ are in accordance with equations $\mathrm{Ep}=-0.0614 \mathrm{pH}+0.573$ (Figure 4) and $\mathrm{Ep}=-0.0558 \mathrm{pH}$ +0.7528 (Figure 4), respectively. For a Nernstian process whose number of transferred electrons is equal to number of transferred protons, the slope would be expected to be $-59 \mathrm{mV} \mathrm{pH}^{-1}$ unit. This suggests that the numbers of electrons and protons transferred in the redox reaction of DA and PAR are equal.
3.4. Effects of Accumulation Time. Anodic peak currents, obtained from DPV experiments, vary accumulation time for $100 \mu \mathrm{M}$ DA and $100 \mu \mathrm{M}$ PAR. Initially, peak currents for these compounds increase with accumulation time up to $60 \mathrm{~s}$; however, after $60 \mathrm{~s}$ of accumulation time, the peak currents reach a slight increase and then plateau. As a consequence, the accumulation time of $60 \mathrm{~s}$ was chosen as an optimum time for further experiments.

\subsection{Linear Dynamic Range and Detection Limit of the Method.} The electrochemical response of simultaneous additions of DA and PAR in a $0.1 \mathrm{M}$ PBS pH 7 using MWCNTs/GCE is depicted in Figures 5 and 6 . Figure 5 shows differential pulse voltammograms and corresponding calibration curves obtained at MWCNTs/GCE in various concentrations of $\mathrm{DA}$ and PAR. For DA a linear dynamic range from $1 \mu \mathrm{M}$ to $540 \mu \mathrm{M}$, with calibration equation Ip $(\mu \mathrm{A})=0.7209 \mathrm{c}$ $(\mu \mathrm{M})+0.3521\left(\mathrm{R}^{2}=0.9954\right)$, and a detection limit of $0.098 \mu \mathrm{M} \quad(\mathrm{S} / \mathrm{N}=3)$ were obtained. A linear relationship was found for PAR in the range of 3 to $300 \mu \mathrm{M}$ with calibration equation Ip $(\mu \mathrm{A})=0.9511 \mathrm{c}(\mu \mathrm{M})+0.8086\left(\mathrm{R}^{2}=\right.$ 0.9989 ), and a detection limit of $0.15 \mu \mathrm{M}$. Figure 6 displays hydrodynamic chronoamperogram response of the rotated modified electrode $(2500 \mathrm{rpm})$ with successive injection of $\mathrm{DA}$ and PAR at an applied potential of $0.4 \mathrm{~V}$ in PBS $(\mathrm{pH}$ 7). For DA, a linear dynamic range was from 3 to $560 \mu \mathrm{M}$. Calibration equation Ip $(\mu \mathrm{A})=0.3288 \mathrm{c}(\mu \mathrm{M})+2.1383\left(\mathrm{R}^{2}\right.$ $=0.9908)($ Inset B) and a detection limit of $0.21 \mu \mathrm{M}(\mathrm{S} / \mathrm{N}=$ 3 ) were obtained. For PAR, a linear relationship was in the range of 3 to $330 \mu \mathrm{M}$. Calibration equation $\operatorname{Ip}(\mu \mathrm{A})=0.3833 \mathrm{c}$ $(\mu \mathrm{M})+2.9184\left(\mathrm{R}^{2}=0.9911\right)($ Inset $\mathrm{C})$ and a detection limit of $0.18 \mu \mathrm{M}$ were obtained. Our proposed method showed low detection limit, wide linear dynamic range, and high sensitivity.

3.6. Repeatability and Long-Term Stability of the Electrode. Thus, the repeatability of the analytical signal has been studied. Indeed, the relative standard deviation (RSD) of $1.31 \%$ and $2.16 \%$ for $100 \mu \mathrm{M} \mathrm{DA}$ and $100 \mu \mathrm{M}$ PAR, respectively, in ten consecutive determinations has been obtained. Another attraction of the proposed modified electrode is that the resulting modified electrode is of a good longterm stability. Stability of the proposed electrode was tested by measuring the decrease in voltammetric current during repetitive DPV measurements of DA and PAR in solution or air. For example, determination of $100 \mu \mathrm{M} \mathrm{DA}$ and $100 \mu \mathrm{M}$ PAR in $0.1 \mathrm{M}$ PBS (pH 7), when the modified electrode was subjected to an experiment every 1 hour, after $24 \mathrm{~h}$ gave less than $8 \%$ and $10 \%$ decrease in the voltammetric currents of DA and PAR, respectively. When the electrode was stored in the atmosphere for 7 days, the currents response of DA and PAR reduced less than $13 \%$ and $15 \%$, respectively, when the electrode was subjected to the solution containing $100 \mu \mathrm{M}$ DA and $100 \mu \mathrm{M}$ PAR.

3.7. Interference Studies. The effect of common interfering species in solutions of $50 \mu \mathrm{M}$ DA and $50 \mu \mathrm{M}$ PAR under our optimum conditions was investigated. The results are 
TABLE 1: Maximum tolerable concentrations for common interfering species.

\begin{tabular}{lcc}
\hline Interfering species & $\mathrm{DA}$ & $\mathrm{PAR}$ \\
& $C_{\text {int }} / \mu \mathrm{M}$ & $C_{\text {int }} / \mu \mathrm{M}$ \\
\hline L-histidine & 1300 & 1100 \\
Tryptophan & 900 & 600 \\
L-alanine & 1200 & 1100 \\
L-glutamic acid & 1600 & 1400 \\
Uric acid & 350 & 200 \\
Ascorbic acid & 400 & 700 \\
Aspartic acid & 3000 & 2500 \\
\hline
\end{tabular}

$C_{\text {int }}$ refers to interfering compound concentration.

TABLE 2: Determination of DA and PAR in human serum and human urine with MCNTs/GCE.

\begin{tabular}{lccccccccc}
\hline Analyte & \multicolumn{1}{c}{ Added $(\mu \mathrm{M})$} & Found $^{\mathrm{a}}(\mu \mathrm{M})$ & R.S.D. (\%) & \multicolumn{2}{c}{ Recovery $(\%)$} \\
& DA & PAR & DA & PAR & DA & PAR & DA & PAR \\
\hline $\begin{array}{l}\text { Human } \\
\text { serum }\end{array}$ & 0.0 & 0.0 & 0.0 & 0.0 & - & - & - & - \\
& 10.0 & 5.0 & 9.84 & 4.96 & 1.4 & 2.5 & 98.4 & 99.2 \\
& 20.0 & 10.0 & 19.58 & 9.86 & 1.7 & 2.1 & 97.9 & 98.6 \\
\hline $\begin{array}{l}\text { Human } \\
\text { urine }\end{array}$ & 0.0 & 0.0 & 0.0 & 0.0 & - & - & - & - \\
& 10.0 & 5.0 & 9.76 & 4.87 & 1.5 & 2.7 & 97.6 & 97.4 \\
& 20.0 & 10.0 & 19.47 & 9.81 & 1.1 & 2.3 & 97.3 & 98.1 \\
\hline
\end{tabular}

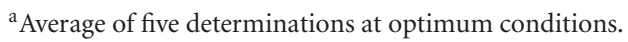

TABle 3: Table Determination of DA and PAR in in injection and tabelt sample with MWCNTs/GCE.

\begin{tabular}{lccccccc}
\hline \multicolumn{2}{c}{ Added $(\mu \mathrm{M})$} & \multicolumn{2}{c}{ Found $^{\mathrm{a}}(\mu \mathrm{M})$} & \multicolumn{2}{c}{ R.S.D. (\%) } & \multicolumn{2}{c}{ Recovery $(\%)$} \\
DA & PAR & DA & PAR & DA & PAR & DA & PAR \\
\hline 0 & 0 & $43.09^{\mathrm{b}}$ & $21.13^{\mathrm{c}}$ & 2.1 & 2.8 & 102.1 & 98.3 \\
10 & 20 & 52.07 & 31.25 & 1.9 & 2.6 & 98.7 & 97.5 \\
10 & 20 & 40.19 & 39.65 & 1.7 & 2.3 & 98.1 & 101.3 \\
\hline
\end{tabular}

${ }^{a}$ Average of five determinations at optimum conditions.

${ }^{\mathrm{b}}$ This amount is equal to $40.86 \mathrm{mg} / \mathrm{mL}$ DA per Injection.

${ }^{\mathrm{c}}$ This amount is equal to $319.49 \mathrm{mg}$ PAR per tablet.

summarized in Table 1. The tolerance limit listed is the concentration of the interfering species that still gives an error of $\leq 10 \%$ in the determination of DA and PAR. The results show that they do not significantly affect the height of the peak currents for DA and PAR and confirm that the proposed method is free from interference of the most common interferants.

3.8. Analytical Applications. The applicability of the method used for the determination of DA and PAR in human serum, human urine, and drug samples was studied by spiking diluted samples with known amounts of DA and PAR simultaneously. DPVs of unspiked and spiked samples were obtained, and the concentrations of DA and PAR were determined using standard addition method and corresponding calibration plots. The results are summarized in Tables 2 and 3. Good recoveries were obtained for spiked samples providing further evidence that this is a reliable method for the direct determination of DA and PAR in human serum, urine, and pharmaceutical samples.

\section{Conclusion}

In this paper we introduced a sensor based on multiwalled carbon nanotube modified glassy carbon electrode. MWCNTs can increase anodic peak currents by enhancement of electron transfers of dopamine and paracetamol compounds on the electrode surface. The results indicated that MWCNTs/GCE facilitates the simultaneous determination of DA and PAR with good sensitivity and selectivity. The electrode showed high stability in repetitive experiments. The effects of potential interfering compounds were studied, and it was found that the proposed procedure is free from interferences of most common interfering compounds. The proposed sensor was used in determination of DA and PAR in some real samples like human serum and urine, without the necessity of sample pretreatments or timeconsuming extraction or overlapped data analysis, with satisfactory results. The simple fabrication procedure, high speed, reproducibility, high stability, wide linear dynamic range, low detection limit, and high sensitivity suggest that the proposed sensor is an attractive candidate for practical applications.

\section{Acknowledgment}

The authors gratefully acknowledge the research council of Arak University for providing financial support for this work.

\section{References}

[1] G. A. Rivas, M. D. Rubianes, M. C. Rodríguez et al., "Carbon nanotubes for electrochemical biosensing," Talanta, vol. 74, no. 3, pp. 291-307, 2007.

[2] A. Babaei, M. Afrasiabi, S. Mirzakhani, and A. Reza Taheri, "A sensitive determination of acetaminophen in pharmaceutical preparations and biological samples using multi-walled carbon nanotube modified glassy carbon electrode," Journal of the Brazilian Chemical Society, vol. 22, no. 2, pp. 344-351, 2011.

[3] L. G. Shaidarova, A. V. Gedmina, I. A. Chelnokova, and G. K. Budnikov, "Determination of biogenic amines from electrocatalytic responses of graphite electrodes modified with metallic osmium or an osmium oxide-ruthenium cyanide film," Journal of Analytical Chemistry, vol. 63, no. 9, pp. 891896, 2008.

[4] L. G. Shaidarova, I. A. Chelnokova, E. I. Romanova, A. V. Gedmina, and G. K. Budnikov, "Joint voltammetric determination of dopamine and uric acid," Russian Journal of Applied Chemistry, vol. 84, no. 2, pp. 218-224, 2011.

[5] B. H. C. Westerink and W. Timmerman, "Do neurotransmitters sampled by brain microdialysis reflect functional release?" Analytica Chimica Acta, vol. 379, no. 3, pp. 263-274, 1999.

[6] F. S. Felix, C. M. A. Brett, and L. Angnes, "Carbon film resistor electrode for amperometric determination of acetaminophen 
in pharmaceutical formulations," Journal of Pharmaceutical and Biomedical Analysis, vol. 43, no. 5, pp. 1622-1627, 2007.

[7] M. Boopathi, MI. S. Won, and Y. B. Shim, "A sensor for acetaminophen in a blood medium using a $\mathrm{Cu}(\mathrm{II})$-conducting polymer complex modified electrode," Analytica Chimica Acta, vol. 512, no. 2, pp. 191-197, 2004.

[8] S. P. Wilson, D. L. Kamin, and J. M. Feldman, "Acetaminophen administration interferes with urinary metanephrine (and catecholamine) determinations," Clinical Chemistry, vol. 31, no. 6, pp. 1093-1094, 1985.

[9] J. P. Courade, F. Caussade, K. Martin et al., "Effects of acetaminophen on monoaminergic systems in the rat central nervous system," Naunyn-Schmiedeberg's Archives of Pharmacology, vol. 364, no. 6, pp. 534-537, 2001.

[10] T. Yoshitake, J. Kehr, S. Yoshitake, K. Fujino, H. Nohta, and M. Yamaguchi, "Determination of serotonin, noradrenaline, dopamine and their metabolites in rat brain extracts and microdialysis samples by column liquid chromatography with fluorescence detection following derivatization with benzylamine and 1,2-diphenylethylenediamine," Journal of Chromatography B, vol. 807, no. 2, pp. 177-183, 2004.

[11] T. Yoshitake, J. Kehr, K. Todoroki, H. Nohta, and M. Yamaguchi, "Derivatization chemistries for determination of serotonin, norepinephrine and dopamine in brain microdialysis samples by liquid chromatography with fluorescence detection," Biomedical Chromatography, vol. 20, no. 3, pp. 267-281, 2006.

[12] C. Muzzi, E. Bertocci, L. Terzuoli et al., "Simultaneous determination of serum concentrations of levodopa, dopamine, 3O-methyldopa and $\alpha$-methyldopa by HPLC," Biomedicine and Pharmacotherapy, vol. 62, no. 4, pp. 253-258, 2008.

[13] N. Erk, Y. Özkan, E. Banolu, S. A. Özkan, and Z. Zentürk, "Simultaneous determination of paracetamol and methocarbamol in tablets by ratio spectra derivative spectrophotometry and LC," Journal of Pharmaceutical and Biomedical Analysis, vol. 24, no. 3, pp. 469-475, 2001.

[14] N. Erk, "Application of derivative-differential UV spectrophotometry and ratio derivative spectrophotometric determination of mephenoxalone and acetaminophen in combined tablet preparation," Journal of Pharmaceutical and Biomedical Analysis, vol. 21, no. 2, pp. 429-437, 1999.

[15] V. Rodenas, M. S. García, C. Sánchez-Pedreño, and M. I. Albero, "Simultaneous determination of propacetamol and paracetamol by derivative spectrophotometry," Talanta, vol. 52, no. 3, pp. 517-523, 2000.

[16] M. J. Ayora Cañada, M. I. Pascual Reguera, A. Ruiz Medina, M. L. Fernández De Córdova, and A. Molina Díaz, "Fast determination of paracetamol by using a very simple photometric flow-through sensing device," Journal of Pharmaceutical and Biomedical Analysis, vol. 22, no. 1, pp. 59-66, 2000.

[17] A. Criado, S. Cárdenas, M. Gallego, and M. Valcárcel, "Continuous flow spectrophotometric determination of paracetamol in pharmaceuticals following continuous microwave assisted alkaline hydrolysis," Talanta, vol. 53, no. 2, pp. 417-423, 2000.

[18] A. Eustaquio, M. Blanco, R. D. Jee, and A. C. Moffat, "Determination of paracetamol in intact tablets by use of near infrared transmittance spectroscopy," Analytica Chimica Acta, vol. 383, no. 3, pp. 283-290, 1999.

[19] M. L. Ramos, J. F. Tyson, and D. J. Curran, "Determination of acetaminophen by flow injection with on-line chemical derivatization: investigations using visible and FTIR spectrophotometry," Analytica Chimica Acta, vol. 364, no. 1-3, pp. 107-116, 1998.
[20] J. L. Vilchez, R. Blanc, R. Avidad, and A. Navalon, "Spectrofluorimetric determination of paracetamol pharmaceuticals and biological fluids," Journal of Pharmaceutical and Biomedical Analysis, vol. 13, no. 9, pp. 1119-1125, 1995.

[21] J. A. Murillo Pulgarín and L. F. García Bermejo, "Flowinjection stopped-flow spectrofluorimetric kinetic determination of paracetamol based on its oxidation reaction by hexacyanoferrate(III)," Analytica Chimica Acta, vol. 333, no. 1-2, pp. 59-69, 1996.

[22] T. Németh, P. Jankovics, J. Németh-Palotás, and H. KoszegiSzalai, "Determination of paracetamol and its main impurity 4-aminophenol in analgesic preparations by micellar electrokinetic chromatography," Journal of Pharmaceutical and Biomedical Analysis, vol. 47, no. 4-5, pp. 746-749, 2008.

[23] K. R. Ing-Lorenzini, J. A. Desmeules, M. Besson, J. L. Veuthey, P. Dayer, and Y. Daali, "Two-dimensional liquid chromatography-ion trap mass spectrometry for the simultaneous determination of ketorolac enantiomers and paracetamol in human plasma. Application to a pharmacokinetic study," Journal of Chromatography A, vol. 1216, no. 18, pp. 3851-3856, 2009. 


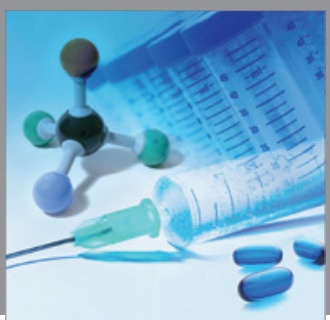

International Journal of

Medicinal Chemistry

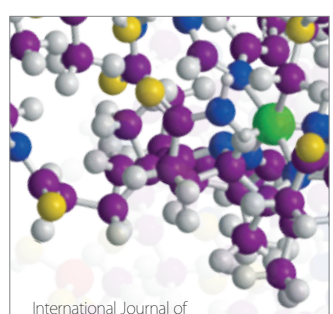

Carbohydrate Chemistry

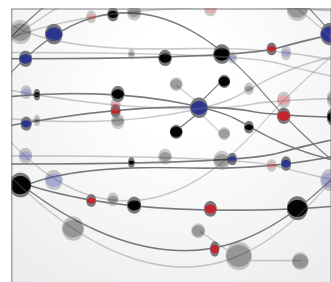

The Scientific World Journal
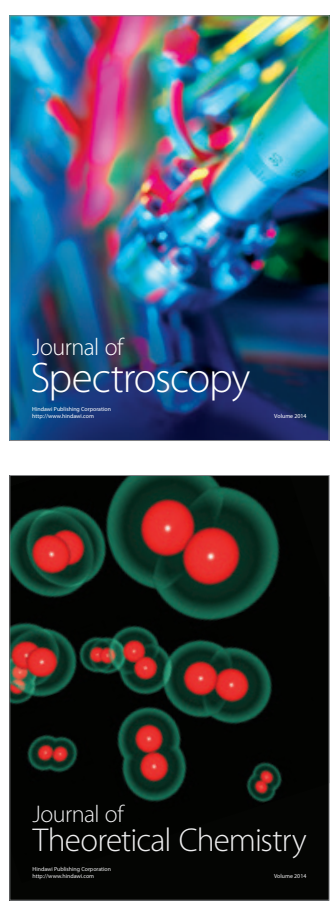
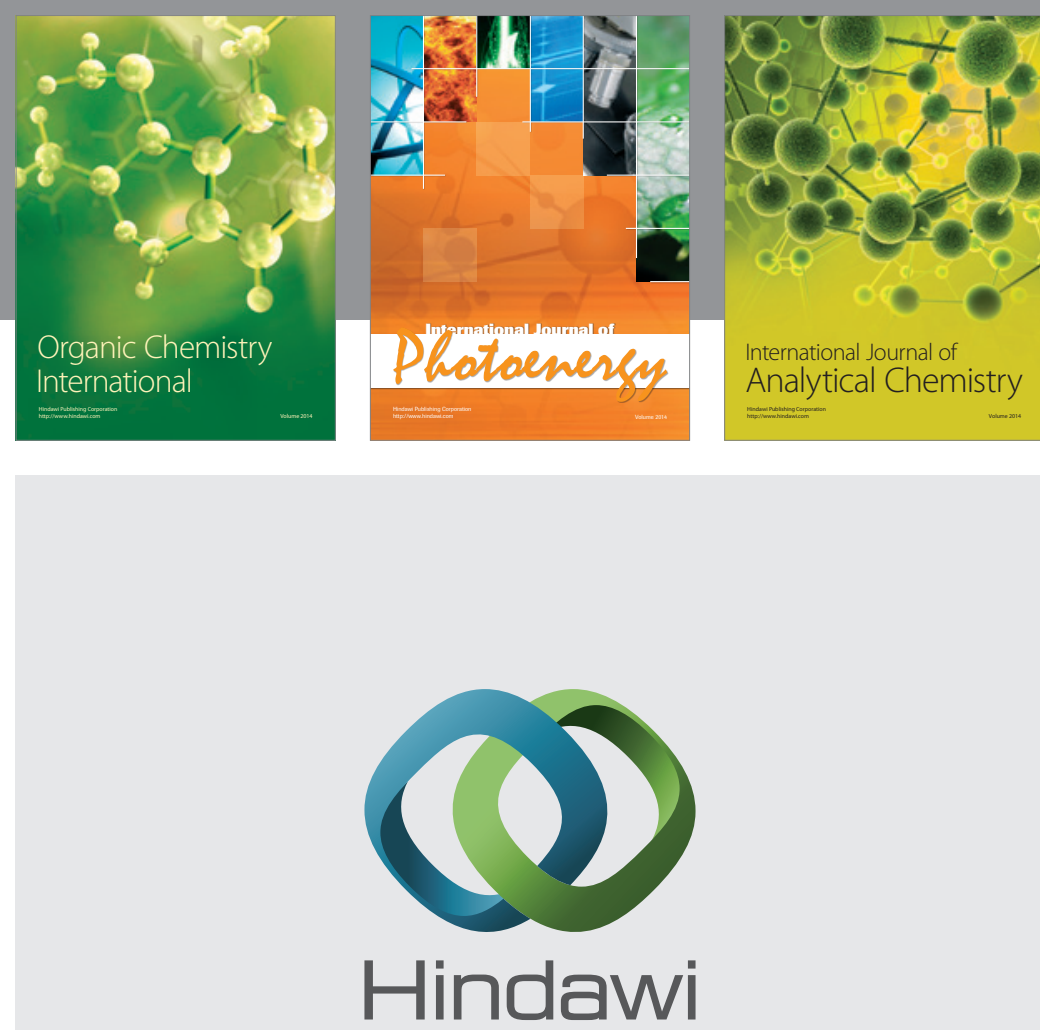

Submit your manuscripts at

http://www.hindawi.com
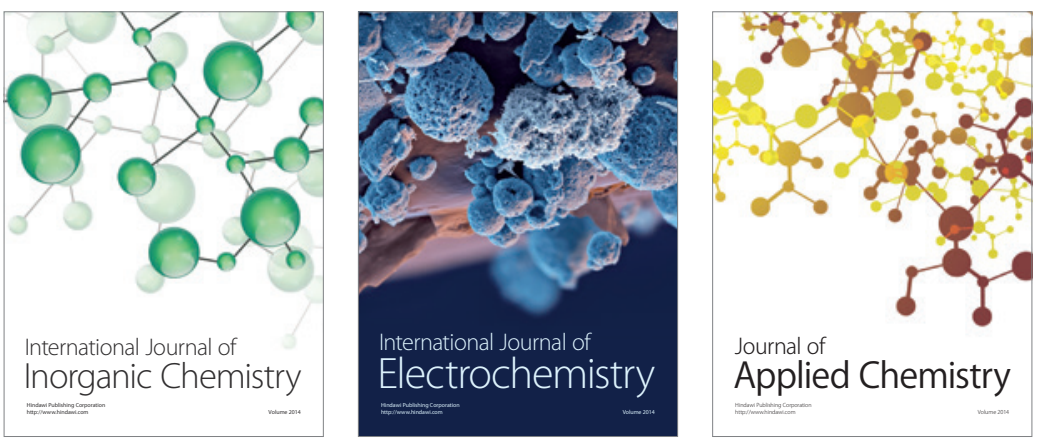

Journal of

Applied Chemistry
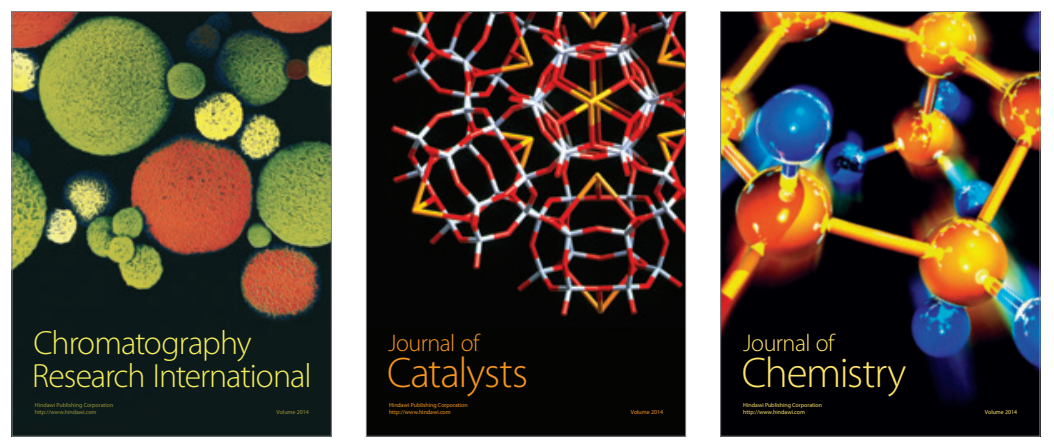
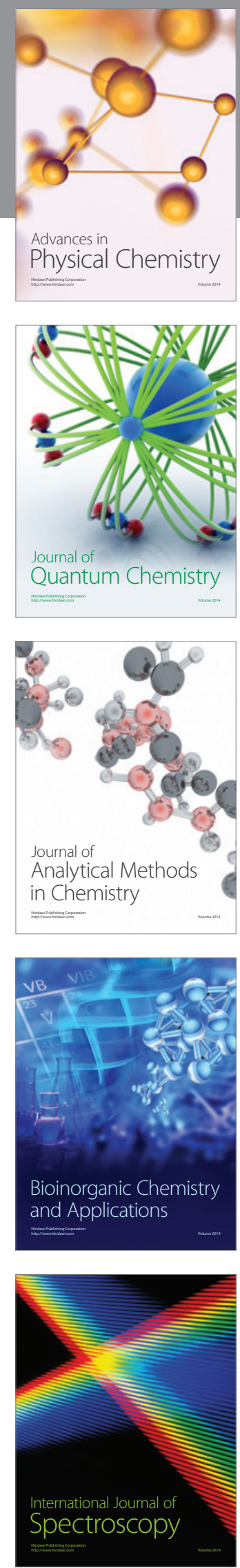